\title{
HIV Drug Efavirenz Inhibits CYP21A2 Activity with Possible Clinical Implications
}

\begin{abstract}
Jana Malikova ${ }^{1,2,3^{*}}$, Tanja Haamberg ${ }^{1 *}$, Ralph Fingerhut ${ }^{4}$, Susanna Sluka ${ }^{4}$, Michael Gröss ${ }^{5}$, Simone Brixius-Anderko ${ }^{6}$, Rita Bernhardt' ${ }^{6}$, Jane McDougall ${ }^{7}$, Amit V. Pandey ${ }^{1,2}$, Christa E. Flück ${ }^{1,2}$

${ }^{1}$ Department of Pediatrics (Division of Pediatric Endocrinology and Diabetology), Inselspital, Bern University Hospital, University of Bern, Switzerland; '2Department of BioMedical Research, Inselspital, Bern University Hospital, University of Bern, Switzerland; ${ }^{3}$ Department of Pediatrics, $2^{\text {nd }}$ Faculty of Medicine, Charles University in Prague and University Hospital Motol, Prague, Czech Republic; 'S Swiss Newborn Screening Laboratory, Children's Research Center (CRC), University Children's Hospital of Zurich, Zurich, Switzerland, ${ }^{5}$ Department of Nephrology and Hypertension, Inselspital, Bern University Hospital, University of Bern, Switzerland, ${ }^{6}$ Department of Biochemistry, Faculty of Technical and Natural Sciences, Saarland University, Saarbrücken, Germany, ${ }^{7}$ Department of Pediatrics (Division of Neonatology), Inselspital, Bern University Hospital, University of Bern, Switzerland.
\end{abstract}

${ }^{*}$ contributed equally

Corresponding author:

Christa E. Flück

Pediatric Endocrinology and

Diabetology, University

Children's Hospital Bern,

Inselspital Bern, Freiburgstrasse

15 / C845, 3010 Bern,

Switzerland

Email:

christa.flueck@dbmr.unibe.ch

Key words: HIV treatment, efavirenz, 21-hydroxylase deficiency, androgens, adrenal insufficiency, congenital adrenal hyperplasia, neonatal screening

\begin{abstract}
Background: HIV drugs lopinavir and ritonavir have been recently reported to cause transient adrenal insufficiency in preterm newborns. We, therefore, considered HIV drugs as a cause of transient elevation of 17-hydroxyprogesterone (17OHP) in a neonatal screening test for congenital adrenal hyperplasia (CAH) in a preterm girl exposed to zidovudine, efavirenz, tenofovir, and emtricitabine.
\end{abstract}

Objective: So far HIV drugs have not been tested for their effect on steroidogenesis and steroidogenic enzyme CYP21A2 specifically in an in vitro system.

Methods: We tested the effect of efavirenz, tenofovir, emtricitabine, and zidovudine on steroidogenesis of human adrenal H295R cells. Cells were treated with drugs at different concentrations including concentrations in therapeutic use. The effect on CYP21A2 activity was assessed by testing the conversion of radiolabeled 17OHP to 11deoxycortisol. Cell viability was tested by an MTT assay. In addition, recombinant produced and purified human CYP21A2 protein was used to assess the direct drug effect on CYP21A2 activity.

Results: We observed significantly decreased CYP21A2 activity in both in vitro testing systems after treatment with efavirenz at therapeutic concentrations. Moreover, efavirenz affected cell viability. By contrast, the other test drugs did not affect steroidogenesis. Follow-up of our patient revealed elevated 17OHP and androgens during the first weeks of life, but values normalized spontaneously. Genetic testing for CYP21A2 mutations was negative. Thus whether transient elevation of $170 H P$ in this baby was due to a drug effect remains unsettled.

Conclusion: The HIV drug efavirenz inhibits CYP21A2 activity in vitro through direct interaction with enzyme catalysis at therapeutic concentrations. This may have clinical implications for HIV treatment in children and adults. However, so far clinical data are scarce, and further studies are needed to draw clinical conclusions.

\section{Introduction}

Adrenal insufficiency (Al) may be a life-threatening condition due to inadequate production of glucocorticoids and mineralocorticoids. It is classified as primary $\mathrm{Al}(\mathrm{PAl})$, with the underlying cause in the adrenals and as secondary $\mathrm{Al}$, with the underlying defect in the hypothalamic-pituitary control of the adrenals. In newborns, congenital adrenal hyperplasia (CAH) due to genetic mutations in the CYP21A2 gene is the leading cause of PAI and affects about 1 in $10^{\prime} 000-15^{\prime} 000$ newborns in Europe (1-3). CYP21A2 is essential for both mineralocorticoid and glucocorticoid production because it mediates the 21hydroxylation of progesterone to deoxycorticosterone and 17-hydroxyprogesterone (17OHP) to 11 - deoxycortisol (2). The severe, classic, salt-wasting form of CYP21A2 deficiency is a potentially lifethreatening condition characterized by low or absent production of cortisol and aldosterone as well as overproduction of adrenal androgens and manifests early in life (1-4). The milder, non-classic form of CAH may manifests later in life predominantly with consequences of adrenal androgen excess. While girls with classic $\mathrm{CAH}$ often manifest with ambiguous genitalia at birth due to intrauterine overproduction of androgens (5), boys do not show physical signs suggestive of $\mathrm{CAH}(4,6)$. Therefore many countries have introduced a neonatal screening program for early diagnosis of $\mathrm{CAH}$ based on blood 17OHP levels reflecting CYP21A2 enzyme deficiency $(3,6)$. 
However, 17OHP blood screening by heel-stick may reveal both false positive and false negative results. Especially challenging is the interpretation of elevated results in preterm (7) or stressed newborns (8). Also, $17 \mathrm{OHP}$ may be elevated in other rarer forms of $\mathrm{CAH}$ such as HSD3B2, CYP11B2 or P450 oxidoreductase deficiencies, which also require prompt corticosteroid replacement therapy $(9,10)$. Furthermore, the activities of adrenal enzymes can be influenced by drugs and toxins, and thereby cause PAI in rare cases. Drugs such as ketoconazole, metyrapone, etomidate, mitotane, and abiraterone are known inhibitors of steroid enzymes including CYP11A1, CYP17A1, CYP21A2 and CYP11B1/2 $(11,12)$.

In recent clinical studies, it has been suggested that some HIV drugs may also affect steroidogenesis. Elevated serum 17OHP and dehydroepiandrosterone (DHEA) levels were found in neonates treated perinatally with HIV-1 protease inhibitors lopinavir and ritonavir $(13,14)$. Three premature babies presented with clinical and biochemical signs of adrenal dysfunction after postnatal treatment with these drugs (13), while a full-term neonate was noted to have high serum 17OHP and potassium levels after pre- and postnatal treatment with lopinavir and ritonavir (14). In our clinic, we also followed a preterm baby of an HIV infected mother for repeatedly high levels of $17 \mathrm{OHP}$ in neonatal screening. Drugs efavirenz, emtricitabine, and tenofovir (Atripla $\AA$ ) were prescribed to the mother during pregnancy to reduce the mother to child transmission of HIV, and the neonate was treated with zidovudine for prevention postnatally. According to current literature (these) HIV drugs have not been tested for a possible effect on steroidogenesis.

The World Health Organization (WHO) reported in 2017 that about 18 million women worldwide were infected with HIV. They also reported that HIV treatment during pregnancy was very effective and reduced the mother to child transmission of an HIV infection from $45 \%$ to $2 \%$ (15). However, this means that a significant number of neonates are exposed to HIV drugs very early in life, and possible adverse effects of drugs might be of significance.

Therefore, motivated by the clinical observations and stimulated by the fact that none of the HIV drugs in routine use have been tested for an effect on adrenal steroidogenesis, we tested some of these drugs for their effect on steroidogenesis, specifically on CYP21A2 activity in vitro.

\section{Materials and Methods}

\section{Case Report}

A $46, X X$ baby girl was born at 26 weeks gestation after premature rupture of membranes to an HIV infected mother. Birth weight was $760 \mathrm{~g}(P 40)$, length $35 \mathrm{~cm}(P$ 60). Because of premature contractions, the mother received 2 doses of betamethasone at 23 5/7 weeks gestation for induction of lung maturation. In addition, the mother was treated with HIV drugs tenofovir, efavirenz and emtricitabine (Atripla $\AA$ ) throughout pregnancy. The newborn was then treated with zidovudine for (post-)exposure prophylaxis during the first four weeks of life (Figure 1). The girl showed a normal physical exam at birth including normal female external genitalia without signs of virilization but received a single dose of hydrocortisone $(0.1 \mathrm{mg} / \mathrm{kg})$ for low blood pressure. Initial laboratory workup in serum revealed normoglycemia, normal electrolytes and a normal $17 \mathrm{OHP}$ ( $80 \mathrm{nmol} / \mathrm{l}$; reference value for $\mathrm{GA}$ and postnatal age $<192 \mathrm{nmol} / /)$. But while glucose and electrolytes remained normal, $17 \mathrm{OHP}$ increased to $292 \mathrm{nmol} / \mathrm{l}$ on day 15 (norm for GA and age $<141 \mathrm{nmol} / \mathrm{l}$ ) and was $132 \mathrm{nmol} / \mathrm{l}$ on day 19 (norm $<104 \mathrm{nmol} /$; DELFIA Neonatal $17 \mathrm{aOH}$-progesterone kit, PerkinElmer, Switzerland), and prompted further workup for possible CAH. ACTH (8.3ng/l; reference range 7.2-63.3) and cortisol (396 nmol//; reference range $171-536 \mathrm{nmol} / \mathrm{l})$ were both normal at three weeks of age. Urine steroid profiling (GC-MS) at 3 and 6 weeks of age revealed elevated progesterone and androgen metabolites. Finally, serum 17OHP normalized after four weeks (Figure 1) and the clinical course was completely unremarkable. The baby was discharged home at the postconceptional age of $361 / 7$ weeks. She is currently 3 years old and healthy.

\section{Urinary steroid profiling}

Urinary steroid profiling was performed by an established, validated in-house method of gas chromatography-mass spectrometry (GC-MS) (16-19). Measurements of spot urines (collected from cotton balls inserted in diapers) were normalized to creatinine (QuantiChrom Creatinine Assay; DICT-500, BioAssay Systems, Hayward, CA, USA). Accordingly, results are expressed in $\mu \mathrm{g} / \mathrm{mmol}$ creatinine (Supplemental Table 1 ) as previously described for healthy neonates during the first year of life (16-18).

\section{Genetic analysis of the CYP21A2 gene}

Three fragments of the CYP21A2 gene were amplified by PCR from genomic DNA using the $\mathrm{CAH}$ StripAssay ${ }^{\circledR}$ (ViennaLab Diagnostics, Vienna, Austria). In addition, all coding sequences of the CYP21A2 gene were sequenced with the Sanger method using internal sequencing primers. For analysis, the CYP21A2 reference sequence NM_000500.6 was used.

\section{In vitro cell assays}

Material: Antiretroviral HIV drugs zidovudine (3'-azido3 'deoxythymidine) and efavirenz were purchased from Sigma-Aldrich (Buchs, Switzerland), tenofovir and emtricitabine from Toronto research chemicals (Brisbane, Canada). Radio-labeled [ $\left.{ }^{3} \mathrm{H}\right]-17-$ hydroxyprogesterone $(17 \mathrm{OHP} ; 50 \mathrm{Ci} / \mathrm{mmol})$ was from American Radiolabel Chemicals Inc. (St. Louis, MO, USA). MTT (3-(4,5-dimethylthiazol-2-yl)-2,5diphenyltetrazolium bromide) was obtained from Sigma-Aldrich (Buchs, Switzerland). The human adrenal carcinoma cell line $\mathrm{NCl}-\mathrm{H} 295 \mathrm{R}$ originates from American Type Culture Collection (ATCC).

$\mathrm{NCl}-\mathrm{H} 295 \mathrm{R}$ cells were cultured under standard conditions $(12,20)$. Test drugs were dissolved in dimethyl sulfoxide (DMSO); final concentrations used for treatment were in and above reported mean 
effective serum concentrations in use for HIV therapy. Cells were grown in twelve well plates. Drugs were added to normal growth medium for 3 and $24 \mathrm{~h}$. Control cells were treated with $0.1 \%(\mathrm{v} / \mathrm{v})$ DMSO. Radiolabeled [ [ $\left.{ }^{3} \mathrm{H}\right]-17-h y d r o x y p r o g e s t e r o n e \quad(50,000$ $\mathrm{cpm} /$ well) was added to the culture medium for the last $90 \mathrm{~min}$ of incubation. Steroids were then extracted from cell supernatants and separated by thin layer chromatography (TLC) as described (21). Steroids were visualized on a Fuji Phospholmager FLA-7000 (Fujifilm, Dielsdorf, Germany) and densitometrically quantified using Multi Gauge software (Fujifilm). The \% conversion of 17OHP to 11-deoxycortisol (11DOC) was taken as a measure of CYP21A2 activity.

The MTT cell proliferation assay was used to determine cell viability and proliferation of $\mathrm{NCl}-\mathrm{H} 295 \mathrm{R}$ cells treated with HIV drugs. In brief, cells were cultured on 96-well plates at a density of 15'000 cells/well in 200 $\mu \mathrm{l}$ medium. After 48 hours cells were treated with the HIV drugs for 3 and 24 hours. Then cell proliferation was assessed by adding $20 \mu \mathrm{l}$ of MTT to the culture medium for 3 hours before reading the absorbance at $540 \mathrm{~nm}$ on a Spectramax M2e microplate reader (Molecular Devices, CA, USA). In this assay, the absorbance at $540 \mathrm{~nm}$ correlates directly to the number of viable cells.

\section{In vitro studies with recombinant CYP21A2 protein}

Human CYP21A2 protein was expressed in E. coli strain C43(DE3) (Lucigen, Middleton, MI, USA) and purified via metal chelate (IMAC) and ion exchange chromatography as described (22). Carbon monoxide difference spectroscopy was carried out for a quantitative enzyme characterization following the typical absorption maximum at $450 \mathrm{~nm}$ with an extinction coefficient of $91 \mathrm{mM}^{-1} \mathrm{~cm}^{-1}$. Human NADPHcytochrome $\mathrm{P} 450$ reductase (POR) was expressed in E. coli C43 (DE3) and purified by IMAC as described (23).

Inhibition studies were performed in reconstituted in vitro assays in $50 \mathrm{mM}$ HEPES buffer (pH 7.4) containing $20 \%$ glycerol and $100 \mu \mathrm{M}$ 1,2-dilauroyl-snglycerol-3-phosphocholine. Before use, the buffer was sonicated in a water bath for 5 minutes for the reconstitution of 1,2-dilauroyl-sn-glycero-3phosphocholine vesicles. The final concentration of human CYP21A2 was $0.1 \mu \mathrm{M}$, and equal amounts of human POR were added. Additionally, the reaction contained an NADPH regeneration system consisting of $5 \mathrm{mM}$ glucose-6-phosphate, $1 \mathrm{mM} \mathrm{MgCl}_{2}$ and glucose-6-phosphate dehydrogenase. The steroid substrate $17 \mathrm{OHP}$ was added at a concentration of 5 $\mu \mathrm{M}$ and the drugs were tested at 5 or $50 \mu \mathrm{M}$ concentration. The substrate concentrations were kept below saturation, but in excess over the $\mathrm{K}_{\mathrm{m}}$ for CYP21A2. The final DMSO concentration was kept below $2 \%$. The reaction was started with $5 \mathrm{mM} \mathrm{NADPH}$ and incubated in a shaking water bath for $4-7 \mathrm{~min}$ at $37^{\circ} \mathrm{C}$. The reaction was quenched with chloroform. Steroids were extracted twice with chloroform, dried and stored at $-20^{\circ} \mathrm{C}$ for HPLC analysis, specifically the measurement of 170HP conversion to 11DOC.
Steroid analysis was finally carried out by RP-HPLC using a Jasco reversed phase HPLC system of the LC900 series (Jasco Inc, Easton, MD, USA) and a 4.6 $\mathrm{mm} \times 125 \mathrm{~mm}$ NucleoDur C18 Isis Reversed Phase column (Macherey-Nagel, Düren, Germany). Samples were measured within $30 \mathrm{~min}$ at $240 \mathrm{~nm}$ and a flow rate of $0.8 \mathrm{~mL} / \mathrm{min}$ with the gradient: $80 \%$ solvent $A(10 \%$ acetonitrile in water) for $13 \mathrm{~min}, 60 \%$ solvent $A$ for 7 $\min , 80 \%$ solvent $\mathrm{B}(100 \%$ acetonitrile) for $2 \mathrm{~min}$ and $80 \%$ solvent $A$ for 8 min.

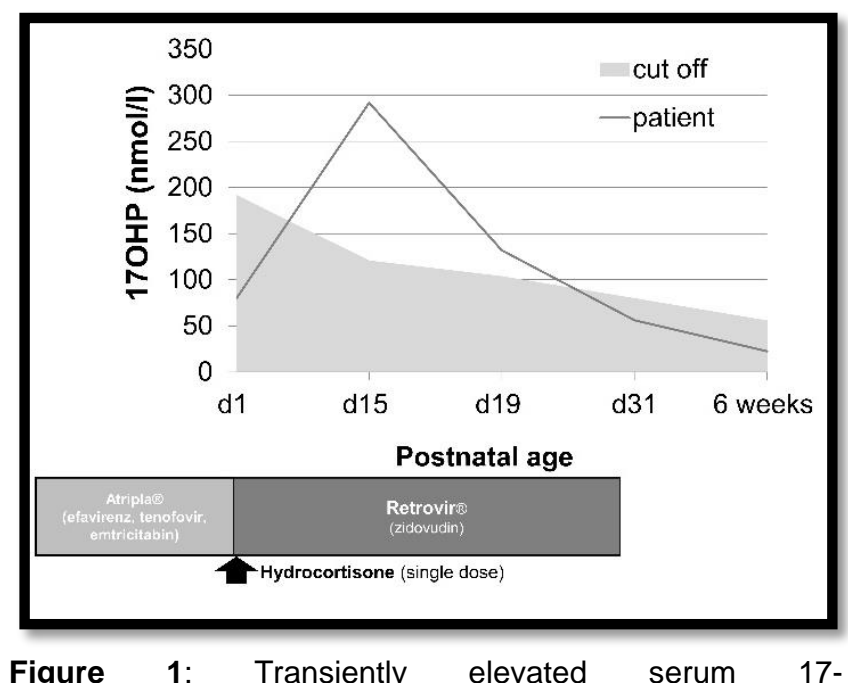
hydroxyprogesterone (17OHP) levels in a newborn under the influence of Atripla $\AA$ (efavirenz, tenofovir, emtricitabine) prenatally and Retrovir ${ }^{\circledR}$ (zidovudine) during 4 weeks postnatally. Note that the newborn received one dose of hydrocortisone in the first 24 hours after birth. Peak 170HP levels were seen at $\mathrm{d} 15$ and normalized by $\mathrm{d} 28$ according to normative values of the Swiss $170 \mathrm{HP}$ neonatal screening test.

In silico protein structure analysis

A 3D crystal structure of human CYP21A2 was obtained from the PDB database (www.rcsb.org) for docking analysis of efavirenz binding (24). However, the structure (PDB \# 4Y8W) has multiple residues missing that creates gaps in the peptide backbone making it unstable during molecular dynamics analysis. A model building using sequence conservation information and secondary structure analysis was needed to fill the gaps and create a complete structure suitable for docking and molecular dynamics calculations. To get the secondary structure information of missing residues we performed sequence alignments with multiple CYP21A2 protein sequences from different organisms (Supplementary Figure 1) and made in-silico calculations with the programs YASARA (25) and WHATIF (26). Missing hydrogen atoms were added with YASARA (25) which was also used for all subsequent computations unless stated otherwise. Afterward, the system was subjected to 500 ps explicit solvent MD simulations at $310 \mathrm{~K}$, preceded by 500 steps of steepest descent and simulated annealing minimization with the AMBER15 force field and the TIP3P water model $(27,28)$. All subsequent $M D$ simulations retained these settings. The resulting minimum energy structure was used with 
AutoDock Vina (29) for docking experiments with efavirenz. Orthorhombic docking was grid established around the central heme. The final poses were selected based on their docking scores and resemblance to the co-crystallized progesterone in the template structure (PDB: 4Y8W). Structure models were depicted with Pymol (www.pymol.org) and rendered as ray-traced images with POVRAY (www.povray.org). Ligand interactions were analyzed.and depicted with LIGPLOT+ (http://www.ebi.ac.uk/thornton-srv/software/LigPlus/).

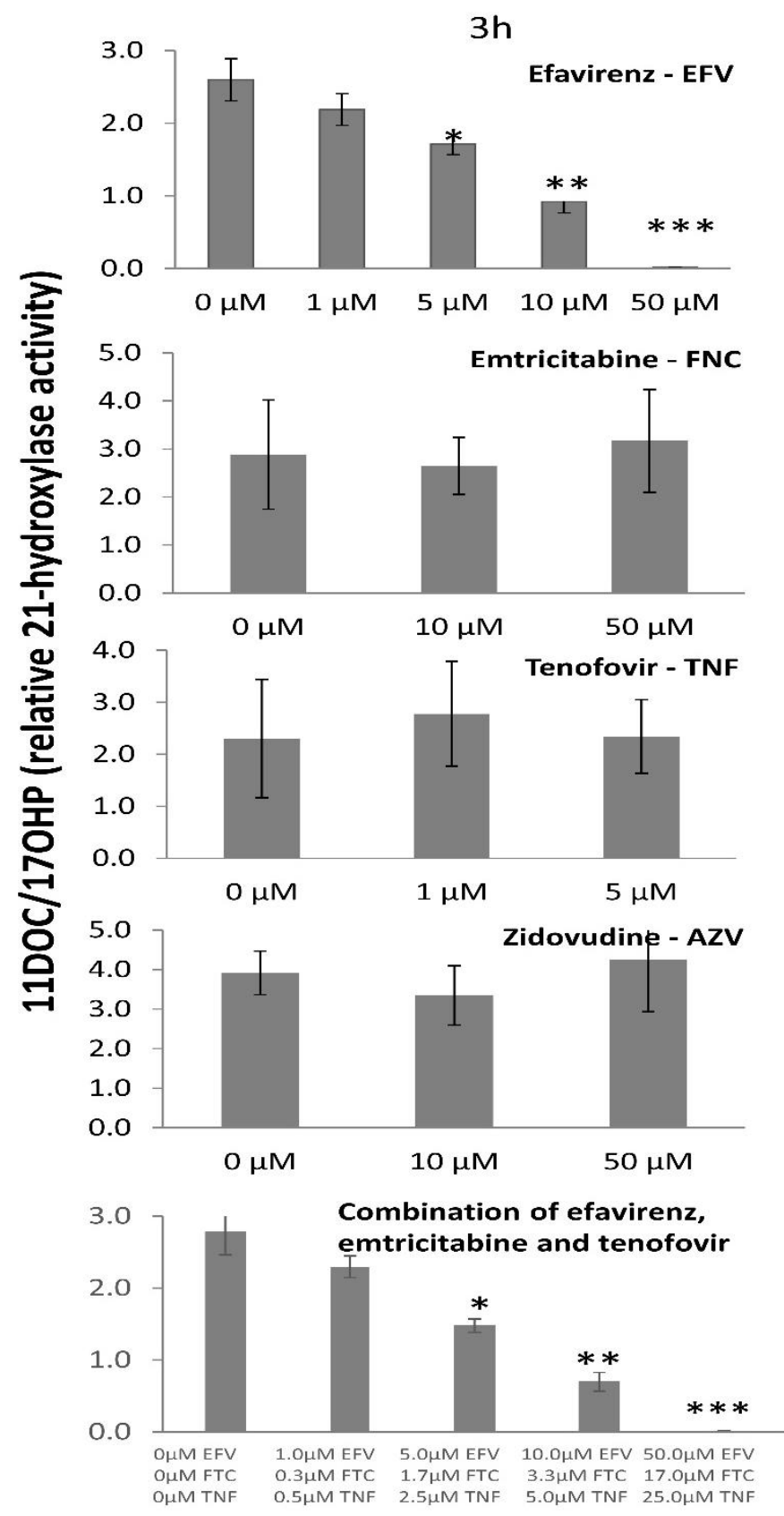

\section{Statistical analysis}

Statistical analysis was performed with Microsoft Excel and software Prism 6 (Graph Pad Software, Inc. San Diego, CA, USA). Student's t-test was used to evaluate the significance of differences between values. Quantitative data represent the mean of two or three independent experiments; error bars indicate the mean \pm SEM. Significance was set at ${ }^{*} p<0.05$ and ${ }^{* *} p<0.01,{ }^{* * *} p<0.001$.
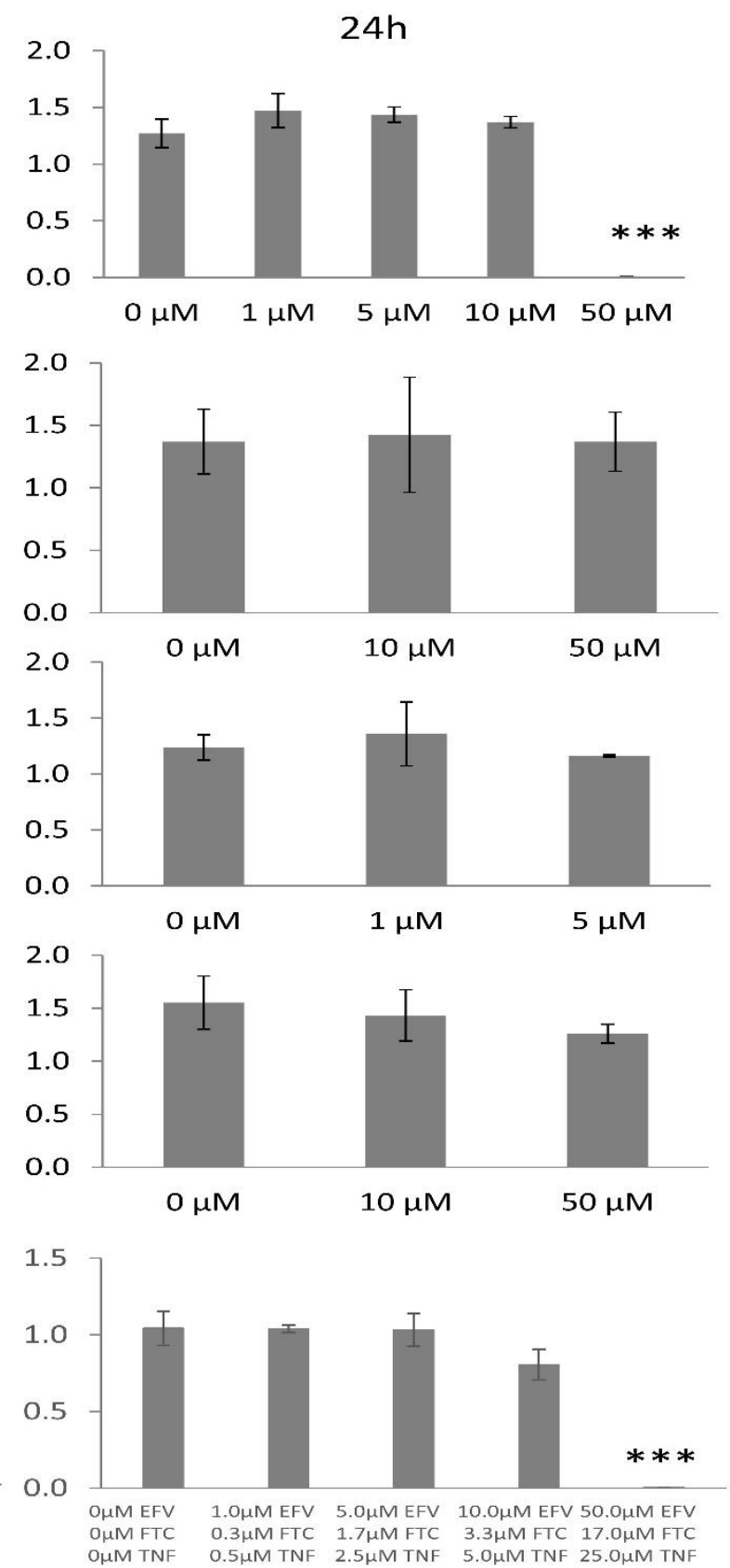

Figure 2 -Efavirenz inhibits CYP21A2 activity at concentrations in therapeutic use, while no effect was seen for the other tested HIV drug compounds. Human adrenal NCI-H295R were treated with efavirenz, emtricitabine, tenofovir, and zidovudine in various concentrations for 3 and 24 hours to test for their effect on steroidogenesis. Steroids were extracted from cell supernatants and separated by thin layer chromatography (TLC). Relative CYP21A2 activity was calculated by assessing the conversion of 17-hydroxyprogesterone (17OHP) to 11-deoxycortisol (11DOC). Data are the mean \pm SEM of two to four independent experiments. ${ }^{\star} p<0.05$ and ${ }^{\star *} p<0.01$, ${ }^{\star \star *} p<0.001$ 


\section{Results}

Biochemical data of neonates exposed to HIV drugs lopinavir and ritonavir suggested an inhibitory effect on adrenal steroidogenesis $(13,14)$. Similarly, we observed elevated serum 170HP levels and urinary steroid profile abnormalities consistent with diminished CYP21A2 and maybe diminished CYP17A1 activities in a preterm girl after exposure to tenofovir, efavirenz and emtricitabine in utero, and zidovudine postnatally (see Case Report; Figure 1). Genetic testing excluded mutations in the CYP21A2 gene.

\section{Efavirenz inhibits CYP21A2 activity}

The effect on steroidogenesis of antiviral HIV drugs zidovudine, emtricitabine, tenofovir, and efavirenz was tested in the adrenal H295R cell line. Efavirenz is a non-nucleoside reverse transcriptase inhibitor. Its reported mean effective serum concentration is 1.6$9.1 \mu \mathrm{M}$

(https://www.medicines.org.uk/emc/product/8659/smp c). The drug was tested at four concentrations $(1 \mu \mathrm{M}$, $5 \mu \mathrm{M}, 10 \mu \mathrm{M}, 50 \mu \mathrm{M})$ after $3 \mathrm{~h}$ and $24 \mathrm{~h}$ incubation. A significant decrease of CYP21A2 activity was observed after $3 \mathrm{~h}$ incubation starting at $5 \mu \mathrm{M}(\mathrm{p}<0.05)$, with a clear additional dose effect at higher concentrations $(10 \mu \mathrm{M}, 50 \mu \mathrm{M} ; \mathrm{p}<0.01, \mathrm{p}<0.001)$ (Figure 2, left panel). By contrast, after 24h incubation CYP21A2 inhibition was only observed at the highest $(50 \mu \mathrm{M})$ efavirenz concentration $(p<0.001)$ suggesting that longer incubation may allow the cells to compensate for the drug effect to some degree (Figure 2, right panel).

Zidovudine and emtricitabine are nucleoside reverse transcriptase inhibitors. Reported mean effective serum concentration for zidovudine is $4.45 \mu \mathrm{M}-8.5 \mu \mathrm{M}$ (https://www.medicines.org.uk/emc/product/6811/smp c) and for emtricitabine it is $4.5 \mu \mathrm{M}-10 \mu \mathrm{M}$ (https://www.medicines.org.uk/emc/product/18/smpc), respectively. H295R cells were treated with zidovudine and emtricitabine in two concentrations $(10 \mu \mathrm{M}$ and $50 \mu \mathrm{M}$ ) for $3 \mathrm{~h}$ and $24 \mathrm{~h}$. Both drugs showed no effect on CYP21A2 activity at either timing (Figure 2). Tenofovir is also a nucleoside reverse transcriptase inhibitor, but by contrast to zidovudine and emtricitabine its mean effective serum concentration is markedly lower $(0.74$ 1.13

$\mu \mathrm{M})$ (https://www.medicines.org.uk/emc/product/771/smpc ). Therefore, tenofovir was tested at lower concentrations of 1 and $5 \mu \mathrm{M}$ for 3 and 24h. No effect on CYP21A2 activity was observed (Figure 2).

As the HIV drugs efavirenz, tenofovir, and emtricitabine are often in use as triple medication Atripla $\AA$, we also tested the three compounds together in our H295R cell system. These experiments revealed the same inhibitory effect on CYP21A2 as observed with efavirenz alone (Figure 2, bottom).

Furthermore, to assess whether the tested drugs may affect H295R cell viability, we performed an MTT cell proliferation assay. Efavirenz starting at $5 \mu \mathrm{M}$ reduced cell proliferation significantly compared to control cells Efavirenz at 10 and $50 \mu \mathrm{M}$ seemed extremely cytotoxic.
The same effect was also observed in H295R cells treated with the combination drug Atripla ${ }^{\circledR}$, while no effect was seen with single treatments of zidovudine, emtricitabine, and tenofovir.

\section{Efavirenz is a direct inhibitor of CYP21A2 activity}

We also tested the direct effect of the four HIV drugs on enzyme catalysis using human recombinant CYP21A2 protein and $17 \mathrm{OHP}$ as a substrate. Similar to the cell culture experiments, we found that efavirenz inhibited CYP21A2 activity to a significant degree, decreasing the product formation to $30 \%$ at a concentration of $50 \mu \mathrm{M}$ efavirenz (Figure 3). By contrast, no effect on enzyme activity was found for the other three test drugs (Figure 3).

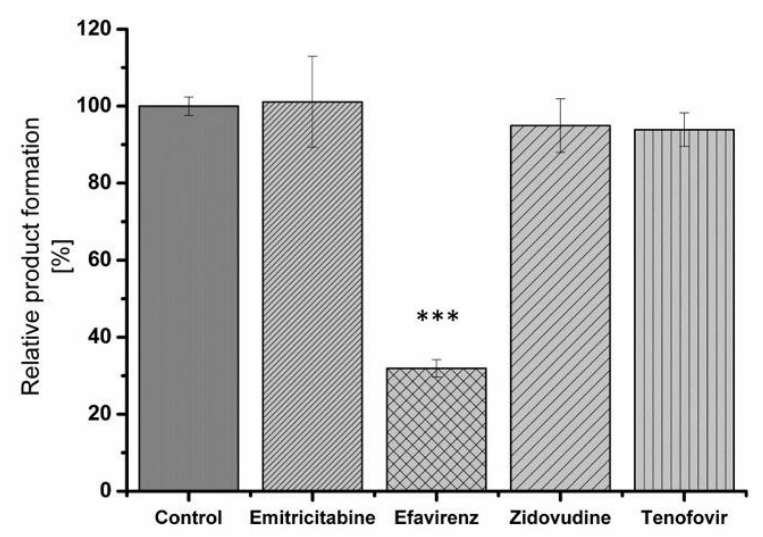

Figure 3 - Effect of HIV-drugs on CYP21A2 activity using human recombinant CYP21A2 protein produced in bacteria. Protein was produced as published. CYP21A2 activity was tested with $5 \mu \mathrm{M} 170 \mathrm{HP}$ as substrate and HIV-drugs at following concentrations: emtricitabine $50 \mu \mathrm{M}$, efavirenz 50 $\mu \mathrm{M}$, zidovudine $50 \mu \mathrm{M}$, and tenofovir $5 \mu \mathrm{M}$. Steroids were extracted and analyzed by RP-HPLC (see Methods).

Computational docking of efavirenz into the human CYP21A2 crystal structure

Efavirenz was docked into the crystal structure of human CYP21A2 using Autodock VINA (Figure 4A). Superimposition of CYP21A2 structures with either progesterone or efavirenz docked into the active site revealed similarities in binding poses (Figure 4B and $4 \mathrm{C})$. We observed a distance of $2.8 \AA$ between efavirenz and heme iron at the active site of CYP21A2 (Figure 4A). Efavirenz is a smaller molecule than progesterone and may achieve several potential binding poses inside the CYP21A2. However, the occupation of the CYP21A2 catalytic site by efavirenz would inhibit the binding and metabolism of CYP21A2 steroid substrates. A comparison of the CYP21A2 and CYP17A1 crystal structures in complex with steroid substrates and docked efavirenz into the crystal structure of CYP21A2 revealed similarities in interacting residues and the distance of the efavirenz nitrogen to the central heme iron of CYP21A2 was in similar range (Figure 4A). Binding of efavirenz with CYP21A2 shares many similarities with natural substrates of CYP21A2 with identical active site residues such as Ser109, Gly292, and Leu364 involved in binding for both chemicals (Figure 4B and $4 \mathrm{C})$. 


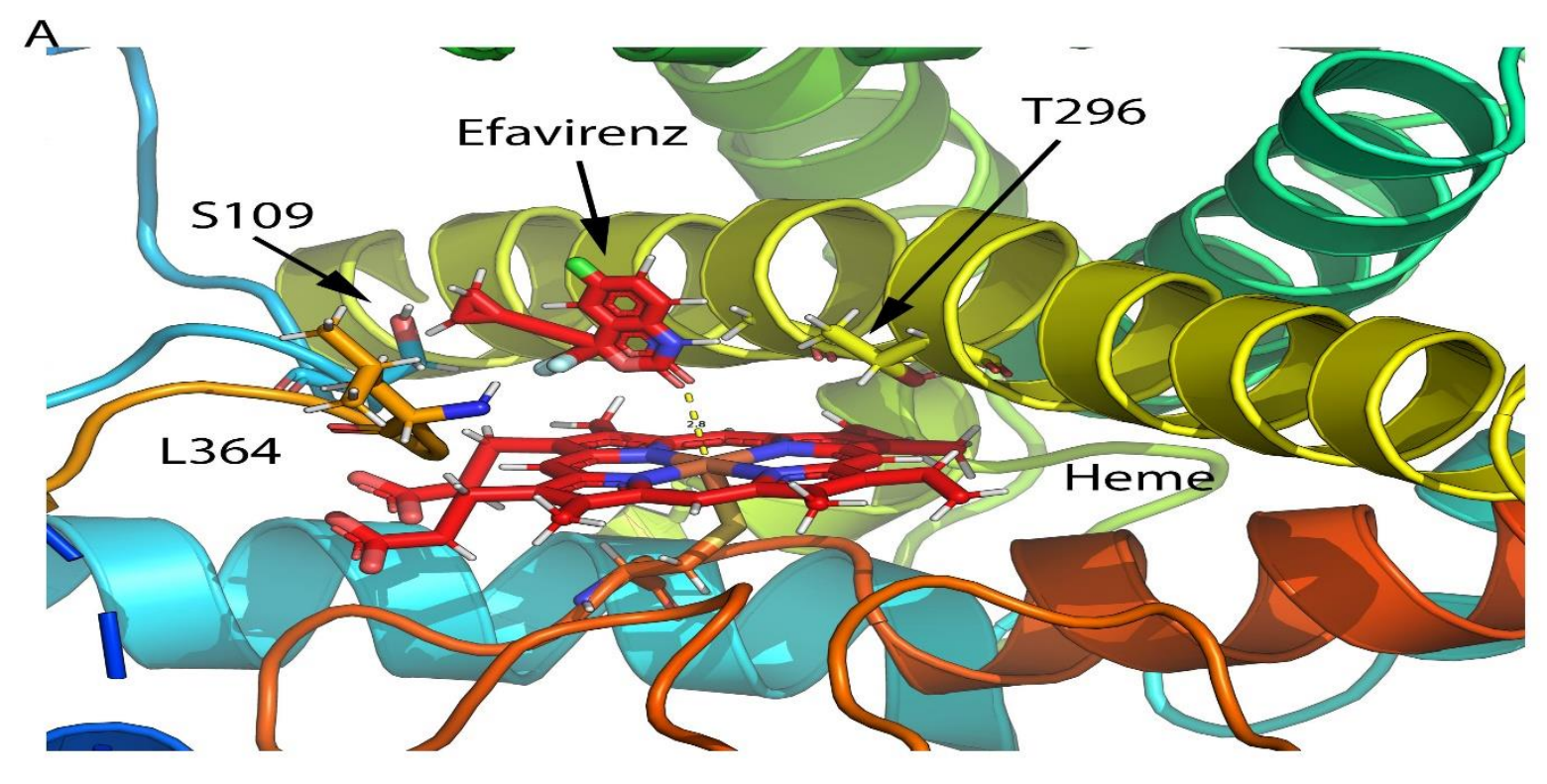

B

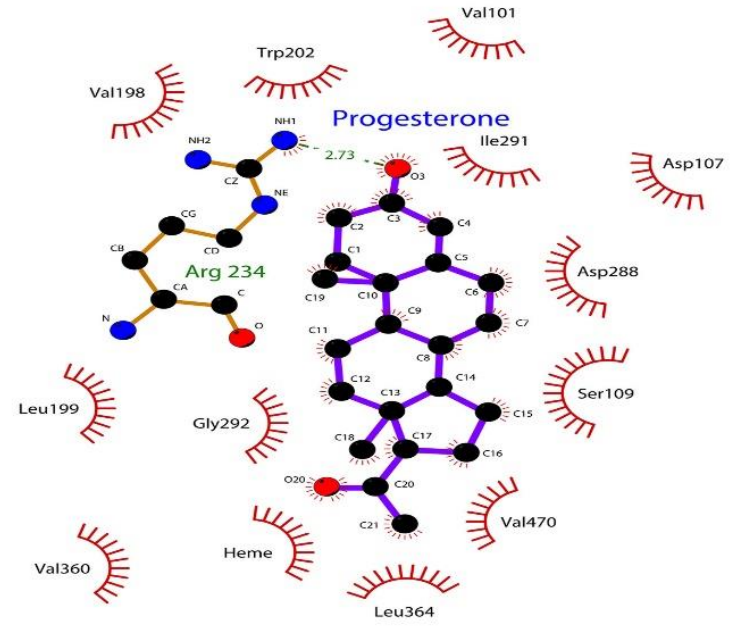

CYP21A2 with Progesterone
C

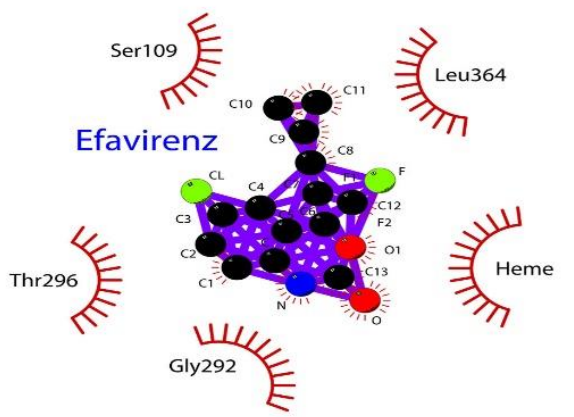

CYP21A2 with Efavirenz

Figure 4 -Structure analysis of HIV-drug efavirenz interaction with the CYP21A2 enzyme. A. Efavirenz docked into the protein structure of CYP21A2. B. Progesterone versus C. Efavirenz binding poses revealed by the CYP21A2 structure and docking studies.

\section{Discussion}

Laboratory investigations of neonates exposed to HIV drugs suggest that these compounds may alter adrenal steroidogenesis $(13,14)$. However, so far these drugs had not been tested for their possible effect on adrenal steroidogenesis. In this study, we show that the antiretroviral drug efavirenz inhibits steroidogenic enzyme CYP21A2 at therapeutic concentrations in human adrenal $\mathrm{NCl}-\mathrm{H} 295 \mathrm{R}$ cells and in direct kinetic protein interaction assays. Our bioinformatic studies suggest that efavirenz is a direct competitor to substrates of the enzyme. By contrast, no inhibitory effect on CYP21A2 activity was found for zidovudine, emtricitabine, tenofovir.

Medications in use for HIV treatment fall in different categories concerning drug safety (https://aidsinfo.nih.gov/guidelines). Tested drugs suspected to inhibit steroidogenesis are listed in the category characterized by limited experience in pregnancy and with incomplete data on teratogenicity, toxicity and drug interactions. In literature, efavirenz has been linked to congenital anomalies in monkeys and humans in some studies (https://aidsinfo.nih.gov/guidelines, $(30,31)$ ), but these adverse effects were not confirmed in others $(32,33)$. Currently no restrictions apply to the use of efavirenz during pregnancy, neither in British nor US HIV treatment guidelines (https://www.bhiva.org/pregnancy-guidelines and https://aidsinfo.nih.gov/guidelines). Fetal exposure to tenofovir was shown to lower bone mineral content in infants compared to controls (34). By contrast, no congenital anomalies or adverse effects have been reported with the HIV drug emtricitabine $(33,35,36)$. Concerning interactions of HIV drugs with cytochrome P450 enzymes, nothing was known for steroidogenic P450s so far. But ritonavir has been reported to inhibit 
drug metabolizing CYP2D6 and CYP3A4 $(37,38)$, while an enzyme induction of ritonavir/lopinavir on CYP1A2 and CYP2C9 and CYP2C19 activities has been observed (39). These drugs have not been tested for their effect on CYP21A2 in this studies, but are currently being tested in cell experiments with preliminary results showing an inhibitory effect of lopinavir but not ritonavir on CYP21A2 and less on CYP17A1.

Overall these results suggest that HIV drugs should be carefully tested for their possible effect on P450s including steroidogenic P450 enzymes as this may have clinical implications. Mild inhibition of adrenal steroid biosynthesis may not have consequences in healthy individuals, but can result in inability to sustain stressful situations with severe disease where within minutes there is a high demand for stress hormones. In addition, long term lowgrade inhibition of CYP21A2 or other steroid enzyme activities may lead to an imbalance between adrenal corticosteroids and androgens with all its consequences. This is best exemplified by late-onset CAH due to mild CYP21A2 deficiency. Such effect may also result from medications interfering with steroid enzyme activities as shown for antiepileptic drugs, which can cause an increase in androgen production and a polycystic ovary syndrome phenotype $(40,41)$.

The premature baby described in our case report showed positive newborn screening for transient elevation of plasma 17OHP and increased urinary excretion of androgens, estrogens and progesterones after treatment with HIV drugs during fetal life (tenofovir, efavirenz, emtricitabine) and postnatally (zidovudine). While elevated plasma 17OHP with neonatal screening motivated us to investigate the effect of the HIV drugs in question on CYP21A2 activity, elevated urinary excretion of progesterones may not be explained by CYP21A2 inhibition but rather by CYP17A1 deficiency. On the other hand, CYP17A1 deficiency decreases androgen production. Thus the abnormal biochemical findings in our case with spontaneous resolution may or may not have been due to an adverse drug effect (of efavirenz). However, our in vitro and in silico studies show that such an effect is clearly seen for efavirenz. Its impact should be further explored in larger clinical studies. It is therefore important to bring the possible inhibitory effect of HIV drugs on adrenal steroidogenesis to the attention of the HIV community, as it may have clinical implications beyond the neonatal age.

In conclusion, HIV drug efavirenz inhibits CYP21A2 activity in human adrenal $\mathrm{NCl}-\mathrm{H} 295 \mathrm{R}$ cells at therapeutic concentrations apparently by a competitive mechanism. This effect has been suspected by laboratory abnormalities found in few newborns treated with HIV drugs. Whether this effect is of clinical relevance to the adrenal function in health and disease remains to be seen in larger clinical studies including children and adults under treatment with HIV drugs. So far we suggest to list some HIV drugs (such as efavirenz) as medications that may cause a positive neonatal screening test for elevated $17 \mathrm{OHP}$.

\section{Statements}

5.1. Acknowledgment

We thank the patient and her family for providing the data for the case report.

5.2. Ethics statement

Parents have given written informed consent for the Case Report. The institutional Ethics committee approved the study.

5.3. Disclosure statement

The authors have no conflicts of interest to declare.

5.4. Funding sources

No external funding. This work was performed from university research funds only.

5.5. Author contribution

Project idea: JM, TH, JMD, CEF. Clinical studies: TH, JMD, CEF. Experimental studies: JM, RF, SS, MG, SBA, RB, AVP, CEF. Bioinformatic studies: AVP. Data analysis: JM, AVP, CEF. Manuscript draft: JM, TH, CEF. Manuscript approval: all authors.

\section{References}

1. Speiser PW, Azziz R, Baskin LS, Ghizzoni L, Hensle TW, Merke DP, Meyer-Bahlburg HF, Miller WL, Montori VM, Oberfield SE, Ritzen M, White PC, Endocrine S. Congenital adrenal hyperplasia due to steroid 21-hydroxylase deficiency: an Endocrine Society clinical practice guideline. J Clin Endocrinol Metab 2010; 95:4133-4160

2. Miller WL, Auchus RJ. The molecular biology, biochemistry, and physiology of human steroidogenesis and its disorders. Endocr Rev 2011; 32:81-151

3. Speiser PW, Arlt W, Auchus RJ, Baskin LS, Conway GS, Merke DP, Meyer-Bahlburg HFL, Miller WL, Murad MH, Oberfield SE, White PC. Congenital Adrenal Hyperplasia Due to Steroid 21-Hydroxylase Deficiency: An Endocrine Society Clinical Practice Guideline. J Clin Endocrinol Metab 2018; 103:4043-4088

4. White PC, Speiser PW. Congenital adrenal hyperplasia due to 21-hydroxylase deficiency. Endocr Rev 2000; 21:245-291 5. Goto M, Piper Hanley K, Marcos J, Wood PJ, Wright S, Postle AD, Cameron IT, Mason JI, Wilson DI, Hanley NA. In humans, early cortisol biosynthesis provides a mechanism to safeguard female sexual development. J Clin Invest 2006; 116:953-960

6. White PC. Neonatal screening for congenital adrenal hyperplasia. Nat Rev Endocrinol 2009; 5:490-498

7. van der Kamp HJ, Oudshoorn CG, Elvers BH, van Baarle M, Otten BJ, Wit JM, Verkerk PH. Cutoff levels of 17alpha-hydroxyprogesterone in neonatal screening for congenital adrenal hyperplasia should be based on gestational age rather than on birth weight. J Clin Endocrinol Metab 2005; 90:39043907

8. $\quad \mathrm{Ng}$ PC, Wong GW, Lam CW, Lee CH, Wong MY, Fok TF, Wong W, Chan DC. Pituitary-adrenal response in preterm very low birth weight infants after treatment with antenatal corticosteroids. J Clin Endocrinol Metab 1997; 82:3548-3552

9. Fluck CE. MECHANISMS IN ENDOCRINOLOGY: Update on pathogenesis of primary adrenal insufficiency: beyond steroid enzyme deficiency and autoimmune adrenal destruction. Eur J Endocrinol 2017; 177:R99-R111

10. Miller WL, Fluck CE. Adrenal cortex and its disorders. In: Sperling MA, ed. Pediatric Endocrinology. 4th Ed ed. Pittsburgh: Elsevier; 2014.

11. Fleseriu M, Castinetti F. Updates on the role of adrenal steroidogenesis inhibitors in Cushing's syndrome: a focus on novel therapies. Pituitary 2016; 19:643-653 
12. Malikova J, Brixius-Anderko S, Udhane SS, Parween S, Dick B, Bernhardt R, Pandey AV. CYP17A1 inhibitor abiraterone, an anti-prostate cancer drug, also inhibits the 21 . hydroxylase activity of CYP21A2. The Journal of steroid biochemistry and molecular biology 2017; 174:192-200

13. Simon A, Warszawski J, Kariyawasam D, Le Chenadec J, Benhammou V, Czernichow P, Foissac F, Laborde K, Treluyer JM, Firtion G, Layouni I, Munzer M, Bavoux F, Polak M, Blanche S, Group AFPCS. Association of prenatal and postnatal exposure to lopinavir-ritonavir and adrenal dysfunction among uninfected infants of HIV-infected mothers. JAMA 2011; 306:7078

14. Kariyawasam D, Simon A, Laborde K, Parat S, Souchon PF, Frange P, Blanche S, Polak M. Adrenal enzyme impairment in neonates and adolescents treated with ritonavir and protease inhibitors for HIV exposure or infection. Horm Res Paediatr 2014; 81:226-231

15. https://www.who.int/hiv/data/en/.

16. Dhayat NA, Frey AC, Frey BM, d'Uscio $\mathrm{CH}$, Vogt $\mathrm{B}$ Rousson V, Dick B, Fluck CE. Estimation of reference curves for the urinary steroid metabolome in the first year of life in healthy children: Tracing the complexity of human postnatal steroidogenesis. The Journal of steroid biochemistry and molecular biology 2015; 154:226-236

17. Dhayat NA, Dick B, Frey BM, d'Uscio CH, Vogt B, Fluck $\mathrm{CE}$. Androgen biosynthesis during minipuberty favors the backdoor pathway over the classic pathway: Insights into enzyme activities and steroid fluxes in healthy infants during the first year of life from the urinary steroid metabolome. The Journa of steroid biochemistry and molecular biology 2017; 165:312-322 18. Dhayat NA, Frey AC, Frey BM, d'Uscio CH, Vogt B, Rousson V, Dick B, Fluck CE. Corrigendum to "Estimation of reference curves for the urinary steroid metabolome in the first year of life in healthy children: Tracing the complexity of human postnatal steroidogenesis" [J. Steroid Biochem. Mol. Biol. 154 (2015) 226-236]. The Journal of steroid biochemistry and molecular biology 2018;

19. Bileck A, Verouti SN, Escher G, Vogt B, GroessI M. A comprehensive urinary steroid analysis strategy using twodimensional gas chromatography - time of flight mass spectrometry. Analyst 2018; 143:4484-4494

20. Udhane SS, Legeza B, Marti N, Hertig D, Diserens G, Nuoffer JM, Vermathen P, Fluck CE. Combined transcriptome and metabolome analyses of metformin effects reveal novel links between metabolic networks in steroidogenic systems. Sci Rep 2017; 7:8652

21. Kempna P, Hirsch A, Hofer G, Mullis PE, Fluck CE. Impact of differential $\mathrm{P} 450 \mathrm{c} 17$ phosphorylation by CAMP stimulation and by starvation conditions on enzyme activities and androgen production in $\mathrm{NCl}-\mathrm{H} 295 \mathrm{R}$ cells. Endocrinology 2010; 151:3686-3696

22. Brixius-Anderko S, Schiffer L, Hannemann F, Janocha $B$, Bernhardt R. A CYP21A2 based whole-cell system in Escherichia coli for the biotechnological production of premedrol. Microb Cell Fact 2015; 14:135

23. Schiffer L, Brixius-Anderko S, Hannemann F, Zapp J, Neunzig J, Thevis M, Bernhardt R. Metabolism of Oral Turinabol by Human Steroid Hormone-Synthesizing Cytochrome P450 Enzymes. Drug Metab Dispos 2016; 44:227-237

24. Pallan PS, Wang C, Lei L, Yoshimoto FK, Auchus RJ, Waterman MR, Guengerich FP, Egli M. Human cytochrome P450 21A2, the major steroid 21-hydroxylase: Structure of the enzyme-progesterone substrate complex and rate-limiting $\mathrm{C}-\mathrm{H}$ bond cleavage. J Biol Chem 2015; 290:13128-13143

25. Krieger E, Darden T, Nabuurs SB, Finkelstein A, Vriend G. Making optimal use of empirical energy functions: force-field parameterization in crystal space. Proteins 2004; 57:678-683

26. Vriend G. WHAT IF: a molecular modeling and drug design program. J Mol Graph 1990; 8:52-56, 29

27. Duan Y, Wu C, Chowdhury S, Lee MC, Xiong G, Zhang W, Yang R, Cieplak P, Luo R, Lee T, Caldwell J, Wang J, Kollman P. A point-charge force field for molecular mechanics simulations of proteins based on condensed-phase quantum mechanical calculations. Journal of Computational Chemistry 2003; 24:1999-2012

28. Jorgensen WL, Tirado-Rives J. Potential energy functions for atomic-level simulations of water and organic and biomolecular systems. Proc Natl Acad Sci U S A 2005; 102:6665-6670

29. Trott O, Olson AJ. AutoDock Vina: Improving the speed and accuracy of docking with a new scoring function, efficient optimization, and multithreading. Journal of Computational Chemistry 2010; 31:455-461

30. Knapp KM, Brogly SB, Muenz DG, Spiegel HM, Conway DH, Scott GB, Talbot JT, Shapiro DE, Read JS. Prevalence of congenital anomalies in infants with in utero exposure to antiretrovirals. Pediatr Infect Dis J 2012; 31:164-170 31. Brogly SB, Abzug MJ, Watts DH, Cunningham CK, Williams PL, Oleske J, Conway D, Sperling RS, Spiegel H, Van Dyke RB. Birth defects among children born to human immunodeficiency virus-infected women: pediatric AIDS clinical trials protocols 219 and 219C. Pediatr Infect Dis J 2010; 29:721727

32. Ford N, Mofenson L, Shubber Z, Calmy A, AndrieuxMeyer I, Vitoria M, Shaffer N, Renaud F. Safety of efavirenz in the first trimester of pregnancy: an updated systematic review and meta-analysis. AIDS 2014; 28 Suppl 2:S123-131

33. Sibiude J, Mandelbrot L, Blanche S, Le Chenadec J, Boullag-Bonnet N, Faye A, Dollfus C, Tubiana R, Bonnet D, Lelong $\mathrm{N}$, Khoshnood B, Warszawski J. Association between prenatal exposure to antiretroviral therapy and birth defects: an analysis of the French perinatal cohort study (ANRS CO1/CO11). PLoS Med 2014; 11:e1001635

34. Siberry GK, Jacobson DL, Kalkwarf HJ, Wu JW, DiMeglio LA, Yogev R, Knapp KM, Wheeler JJ, Butler L, Hazra R, Miller TL, Seage GR, 3rd, Van Dyke RB, Barr E, Davtyan M, Mofenson LM, Rich KC, Pediatric HIVACS. Lower Newborn Bone Mineral Content Associated With Maternal Use of Tenofovir Disoproxil Fumarate During Pregnancy. Clin Infect Dis 2015; 61:996-1003

35. Mugo NR, Hong T, Celum C, Donnell D, Bukusi EA, John-Stewart G, Wangisi J, Were E, Heffron R, Matthews LT, Morrison S, Ngure K, Baeten JM, Partners Pr EPST. Pregnancy incidence and outcomes among women receiving preexposure prophylaxis for HIV prevention: a randomized clinical trial. JAMA 2014; 312:362-371

36. https://aidsinfo.nih.gov/guidelines. 2017;

37. Aarnoutse RE, Kleinnijenhuis J, Koopmans PP, Touw DJ, Wieling J, Hekster YA, Burger DM. Effect of low-dose ritonavir (100 mg twice daily) on the activity of cytochrome P450 2D6 in healthy volunteers. Clin Pharmacol Ther 2005; 78:664674

38. Rock BM, Hengel SM, Rock DA, Wienkers LC, Kunze $\mathrm{KL}$. Characterization of ritonavir-mediated inactivation of cytochrome P450 3A4. Mol Pharmacol 2014; 86:665-674

39. Yeh RF, Gaver VE, Patterson KB, Rezk NL, BaxterMeheux F, Blake MJ, Eron JJ, Jr., Klein CE, Rublein JC, Kashuba AD. Lopinavir/ritonavir induces the hepatic activity of cytochrome P450 enzymes CYP2C9, CYP2C19, and CYP1A2 but inhibits the hepatic and intestinal activity of CYP3A as measured by a phenotyping drug cocktail in healthy volunteers. Journal of acquired immune deficiency syndromes 2006; 42:5260

40. Fluck CE, Yaworsky DC, Miller WL. Effects of anticonvulsants on human p450c17 (17alpha-hydroxylase/17,20 lyase) and 3beta-hydroxysteroid dehydrogenase type 2 . Epilepsia 2005; 46:444-448

41. Hamed SA. The effect of epilepsy and antiepileptic drugs on sexual, reproductive and gonadal health of adults with epilepsy. Expert Rev Clin Pharmacol 2016; 9:807-819

(C) Authors 2019 